\title{
GESTÃO DE EXPECTATIVAS NA AUDITORIA INTERNA: O CASO DE UMA INSTITUIÇÃO FEDERAL DE ENSINO
}

\begin{abstract}
MARIZ, Lawrence Praxedes ${ }^{1}$ ARAÚJO, Richard Medeiros de ${ }^{2}$

Recebido em: 2020.05.11 $\quad$ Aprovado em: 2021.02.22 $\quad$ ISSUE DOI: $10.3738 / 1982.2278 .3797$

RESUMO: O presente artigo tem como objetivo compreender como é realizada a gestão de expectativas na unidade de auditoria interna do Instituto Federal de Ciência e Tecnologia do Rio Grande do Norte - IFRN. A metodologia classifica-se quanto aos objetivos, como descritiva e exploratória; quanto aos procedimentos, estudo de caso e pesquisa documental; e quanto à abordagem, qualitativa. Para a coleta de dados, foram utilizados como instrumentos os registros e documentos institucionais, a entrevista individual com o Auditor-Chefe e o grupo focal com os auditores do IFRN. Os dados foram tratados por meio da análise de conteúdo e análise documental. Os resultados demonstraram que a fase de conhecimento (identificação e coleta das expectativas dos key stakeholders) possui uma rotina de procedimentos pré-definida, na qual o principal instrumento utilizado é o Levantamento de Informações. Quanto à fase de consideração das expectativas, verificou-se que a unidade não possui uma rotina de procedimentos para orientar os auditores nessa etapa, podendo provocar fragilidades ao trabalho da auditoria interna. Diante disso e considerando que a literatura aponta que o cenário atual evidencia o surgimento de novas expectativas e a ampliação destas em torno da auditoria interna, conclui-se que o momento da análise das expectativas das principais partes interessadas merece atenção, sendo relevante estabelecer procedimentos de orientação aos auditores, a fim de afastar ou mitigar as fragilidades detectadas.
\end{abstract}

Palavras-chave: Auditoria interna governamental; Normas de auditoria; Alinhamento estratégico; diferenças de expectativas em auditoria.

\section{EXPECTATION MANAGEMENT IN INTERNAL AUDIT: THE CASE OF A FEDERAL EDUCATION INSTITUTION}

SUMMARY: This article aims to understand how expectations are managed in the internal audit unit of the Instituto Federal de Ciência e Tecnologia do Rio Grande do Norte - IFRN. The methodology is classified as to the objectives, as descriptive and exploratory; as to the procedures, case study and documentary research; and as for the approach, qualitative. For data collection, institutional documents, the individual interview with the Chief Auditor and the focus group with IFRN auditors were used as instruments. The data were treated through content analysis and document analysis. The results showed that the knowledge phase (identification and collection of key stakeholders' expectations) has a pre-defined procedure routine, in which the main instrument used is the Information Survey. As for the consideration phase (meeting expectations), it was found that the unit does not have a routine of procedures to guide auditors in this stage, which may cause weaknesses in the work of the internal audit. Given this and considering that the literature points out that the current scenario shows the emergence of new expectations and the expansion of these around the internal audit, it is concluded that the moment of analysis of the expectations of the key stakeholders deserves attention, being relevant to establish procedures for guidance to auditors in order to remove or mitigate the weaknesses detected.

Keywords: Internal auditing; Standards; Strategic alignment; audit expectations gap.

\section{INTRODUÇÃO}

As discussões recentes sobre o papel e efetividade da auditoria interna demonstram a ampliação e mudanças nas expectativas dos stakeholders em relação a atividade desenvolvida pelos auditores (ERASMUS; COETZEE, 2018).

\footnotetext{
${ }^{1}$ Universidade Federal do Rio Grande do Norte.

${ }^{2}$ Doutor em Administração pelo PPGA/UFRN (2012) e professor do PPGP/UFRN
}

Nucleus, v.18, n.1, abr. 2021 
Por conta disso, estudos apontam que a auditoria interna deve compreender a estratégia e as prioridades da administração, os riscos mais relevantes para a instituição e principalmente as expectativas das partes interessadas, para que tenha condição de fornecer o suporte de que os stakeholders procuram e necessitam (DELOITTE, 2018).

No âmbito do Poder Executivo Federal, o Sistema de Controle Interno (SCIPEF) passou por mudanças em seu arcabouço normativo, com intuito de assegurar o fortalecimento da atividade de auditoria interna governamental, tendo como destaque a consonância com padrões e práticas reconhecidas internacionalmente (IIA, 2017; COSO, 2007; CGU, 2017a).

Essas normas de auditoria descrevem procedimentos a serem realizados quanto à identificação, coleta e consideração das expectativas da alta administração e demais partes interessadas, na fase de elaboração do planejamento das atividades, na emissão de opinião e na comunicação dos resultados (CGU, 2017a; CGU, 2018a).

Pressupõe-se, portanto, que essa previsão normativa proporciona, a priori, o alinhamento de expectativas entre a gestão e a auditoria interna. Principalmente, ao considerar que se espera cada vez mais da auditoria interna adição de valor por meio da prestação de serviços de assessoramento, conforme aponta o Instituto Brasileiro de Governança Corporativa - IBGC (2018).

Sobre isso, a PricewaterhouseCoopers - PWC divulgou os resultados de uma pesquisa, demonstrando que há expectativa para que auditoria interna assuma uma função mais participativa ou proativa no assessoramento, a fim de auxiliar o processo de gerenciamento de riscos (PWC, 2017b). A expectativa requer, principalmente, a mudança de compreensão sobre a forma que a auditoria interna contribui para a gestão, ou seja, a mudança de caráter punitivo ou reativo para um cenário de assessoramento proativo ou preventivo (ATTIE, 2012; FAUSTINO; NASCIMENTO; COSTA, 2016; PWC, 2017b).

Como há evidências na literatura sobre a relação conflituosa entre auditores e auditados no âmbito da administração pública brasileira (MARÇOLA, 2011), bem como registros sobre a má compreensão quanto ao papel da auditoria interna no âmbito universidades e institutos federais (TCU, 2015), verifica-se a necessidade de compreender melhor as novas perspectivas da auditoria interna, especialmente quanto aos procedimentos. Além disso, como a produção acadêmica sobre auditoria interna ainda é baixa e prioritariamente focada no âmbito contábil (MAFRA et al., 2016; OLIVEIRA; CARVALHO, 2008), surge a importância de se compreender com é realizada a gestão de expectativas no âmbito de uma unidade de auditoria interna governamental (UAIG).

Nucleus, v.18, n.1, abr. 2021 
Destarte, o presente artigo focará sua análise na unidade de auditoria interna do Instituto Federal de Educação, Ciência e Tecnologia do Rio Grande do Norte (IFRN). A referida unidade de auditoria está inserida numa instituição que passou na última década por aumento no fluxo orçamentário e transformação estrutural e normativa, em razão da expansão da Rede Federal de Educação Profissional e Tecnológica (RFEPCT).

O IFRN é vinculado ao Ministério da Educação e possui natureza jurídica de autarquia. Atualmente, possui 40.178 (quarenta mil, cento e setenta e oito) alunos matriculados em diversos cursos oferecidos na instituição, da educação básica à pós-graduação. Sua estrutura se divide em Reitoria e 22 (vinte e dois) campi, distribuídos por todo o estado do Rio Grande do Norte (IFRN, 2019a).

Diante disso, a presente pesquisa se norteará pela seguinte pergunta: de que forma é realizada a gestão de expectativas na unidade de auditoria interna do Instituto Federal de Educação, Ciência e Tecnologia do Rio Grande do Norte - IFRN?

O artigo está dividido em quatro seções: na primeira, é abordada a gestão de expectativa; na segunda, é descrito o percurso metodológico; na terceira, são apresentados os resultados e a respectiva análise da pesquisa; e por último, são feitas as conclusões.

\section{GESTÃO DE EXPECTATIVAS NA AUDITORIA INTERNA GOVERNAMENTAL}

As pesquisas sobre a efetividade da auditoria interna estão aumentando e demonstrando a importância e o desafio de compreender os fatores que influenciam esta atividade (ERASMUS; COETZEE, 2018). Coetzee e Erasmus (2017), ao revisarem a literatura, apontaram os seguintes fatores como determinantes para a efetividade da auditoria interna: competência; tamanho/estrutura da unidade de auditoria interna; relação auditoria interna e externa; suporte gerencial; independência; proficiência, escopo de trabalho; status organizacional; papel e serviços da auditoria; qualidade do trabalho; responsabilidades; liderança; organização (suporte e satisfação); e objetividade. Os autores ainda destacaram que a maioria dos estudos abordam esse tema principalmente do ponto de vista da própria auditoria, o que representa uma limitação no estudo. Sobre isso, ainda, observam que pouco estudos investigaram o assunto sob a perspectiva dos auditados.

Desses poucos estudos, verificou-se algumas evidências da contribuição das normas para o alinhamento de expectativas, a necessidade de alinhamento estratégico, necessidade dos auditores terem habilidades apropriadas e a importância da construção de um bom relacionamento com a alta gestão (D’ONZA; LAMBOGLIA; VERONA, 2015). 
Ao defenderem a importância da percepção dos stakeholders (partes interessadas) com relação à efetividade da auditoria interna, Erasmus e Coetzee (2018), em estudo recente, demonstram que as diferenças de expectativas entre a auditoria interna e os stakeholders estão aumentando. Corroborando com as instruções defendidas pelo IIA (2014), que estabelece como estratégico o alinhamento entre a auditoria interna e os principais stakeholders, para que a atividade seja efetiva.

Segundo o IIA (2012), a auditoria interna possui vários stakeholders, sendo a maioria deles independentes. No âmbito do SCIPEF, o Referencial Técnico da Atividade de Auditoria Interna Governamental do Poder Executivo Federal (RT) não limita quem são as partes interessadas, apenas cita especificamente em seu texto: a alta administração, conselho e outras partes interessadas (CGU, 2017a). Sendo assim, o presente artigo, adota apenas a alta administração ou gestão e demais partes interessadas (que podem ser, por exemplo: auditados, órgãos de controle externo e sociedade) para definir quem são os stakeholders da unidade de auditoria interna do IFRN.

Vários estudos apontam, ainda, a existência de conflitos de expectativas em auditoria, ou seja, quando duas partes ou mais possuem expectativas divergentes sobre a auditoria interna (ERASMUS; COETZEE, 2018; ROUSSY, 2013; DELOITTE, 2010). Sendo assim, para reduzir essas diferenças de expectativas a unidade de auditoria interna precisa planejar e executar seu papel de maneira que as partes interessadas tenham suas expectativas satisfeitas, contudo sem comprometer a independência e objetividade inerente à atividade (ERASMUS; COETZEE, 2018; IIA, 2017).

De acordo com Koh e Woo (1998), o conceito de diferenças de expectativas em auditoria varia entre os pesquisadores. Porter (1993) definiu como a lacuna entre as expectativas da sociedade em relação aos auditores e o desempenho dos auditores, conforme percebido pela sociedade. Por outro lado, Jennings et al. (1993) e Lowe (1994) compreendem como a diferença entre o que o público espera da profissão de auditor e o que o profissional realmente fornece.

Existem evidências de diferenças de expectativas em auditoria em vários lugares do mundo (REZA; KARIM, 2018), confirmando que se trata de uma preocupação constante para a auditoria. Além disso, estudos buscaram explicar a presença contínua dos gaps de expectativas (HUMPHREY; MOIZER; TURLEY, 1992; MILLS; BETTNER, 1992; TRICKER, 1982).

De acordo com Ebimobowei (2010), as causas dos gaps podem ser uma combinação de equívocos e ignorância por parte dos usuários; a complicada natureza da atividade de auditoria; as expectativas irracionais; o intervalo de tempo curto para mudar as expectativas da sociedade; a baixa remuneração e práticas inadequadas dos auditores. 
A literatura dedicada ao assunto, além de procurar compreender as causas, passou a fazer sugestões para a minimização das diferenças de expectativas em auditoria. As medidas apontadas pela literatura são resultados da natureza dos gaps de expectativas e os fatores que lhes deram origem. No entanto, ainda que as medidas visem reduzir as diferenças de expectativas em auditoria, o problema da lacuna pode não ser totalmente eliminado (EBIMOBOWEI, 2010).

Jedidi e Richard (2009) entendem que é impossível eliminar as diferenças de expectativas, pois para isso seria necessário estabelecer um significado fixo de auditoria. Contudo, isso não seria possível porque a definição de auditoria está em constante transformação, se sujeitando aos desafios e mudanças conforme o desenvolvimento social, econômico e político.

Diante disso, pesquisas demonstram a importância da gestão de expectativas, traduzido livremente do inglês "managing expectations" (CIIA, 2019; PIPER, 2015). Erasmus e Coetzee (2018) ainda concluem que isto pode levar a maior efetividade da auditoria interna, repercutindo, inclusive, na accountability do setor público.

Tendo em vista que as diferenças de expectativas entre a auditoria interna e os stakeholders estão aumentando, estudos apontam a importância da auditoria interna buscar alinhar estrategicamente seus objetivos com a alta administração e a necessidade de gerenciar as expectativas em auditoria (PWC, 2017a; IBGC, 2018).

Para a PricewaterhouseCoopers - PWC (2017a), é importante que a auditoria interna esteja alinhada estrategicamente com as necessidades e prioridades de todas as partes interessadas (conselhos, gestão e auditores externos), para ser percebida como agregadora de valor, sem desconsiderar a inerente independência e objetividade da atividade (HASS; ABDOLMOHAMMADI; BURNABY, 2006).

Dessa forma, ao considerar a importância de que o planejamento estratégico da organização e o plano de atividades da unidade de auditoria interna precisam estar alinhados (PWC, 2017a; IBGC, 2018), verifica-se a necessidade de se compreender as expectativas dos key stakeholders, pois o alinhamento visa garantir que as funções da auditoria e os principais interessados compartilhem as mesmas prioridades (FEIZIZADEH, 2012).

De acordo com Abdolmohammadi, D’Onza e Sarens (2016, p. 7), o alinhamento entre o plano estratégico da organização e o plano de atividades da auditoria interna "é uma estratégia para garantir a sinergia entre o departamento e a organização como um todo”. Já para o IIA (2019), alinhamento é a posição de concordância ou aliança entre as partes.

Esse alinhamento estratégico requer a construção de uma relação positiva entre gestão e auditoria, pois é necessário um contato frequente com os gestores e participação ativa em reuniões estratégicas (D’ONZA; LAMBOGLIA; VERONA, 2015; PWC, 2017a). Nesse sentido, o IBGC (2018, p. 17) entende que o "plano de auditoria deve trazer as expectativas e prioridades 
de trabalho e deve estar alinhado com as partes interessadas e ser frequentemente revisado e atualizado".

Dessa forma, a gestão de expectativas é apontada como necessária para que a auditoria interna consiga equilibrar as necessidades e expectativas de várias partes interessadas (WEBSTER, 2016). Sobre isso, o PWC (2017a, p. 5) defende que "um plano de gestão de stakeholders eficaz geralmente melhora o alinhamento com o negócio e a atenção da Auditoria Interna, com o consequente foco nos riscos críticos".

A gestão de expectativas das partes interessadas, segundo o PMI (2017), prevê a identificação e análise das expectativas de todas as partes interessadas que podem impactar ou serem impactados pelo projeto e o desenvolvimento de estratégias de gerenciamento apropriadas para o engajamento das partes interessadas nas decisões e execução do projeto.

Como as normas de auditoria possuem grande importância na prescrição de padrões mínimos de qualidade, inclusive para a mitigação das diferenças de expectativas (CREPALDI, 2009; D’ONZA; LAMBOGLIA; VERONA, 2015), a abordagem da gestão de expectativa, neste artigo, considerará os padrões normativos aplicáveis à unidade de auditoria interna governamental - UAIG.

As normas do IIA (2017) destacam a necessidade de identificar e considerar as expectativas das partes interessadas (alta administração, conselho e outras partes) no planejamento das atividades, na comunicação dos resultados, na elaboração dos relatórios e na emissão de opinião. No âmbito do SCIPEF, o Referencial Técnico (RT) prevê várias regras definindo que a unidade de auditoria interna governamental deve coletar e levar em consideração as expectativas da alta administração e demais partes interessadas (CGU, 2017a).

O conteúdo das normas de auditoria já citadas, ao abordarem as expectativas dos stakeholders, destacam três ações da auditoria interna: identificar, coletar e levar em consideração essas expectativas. A identificação e a coleta servem para que a unidade de auditoria interna tome conhecimento das expectativas dos clientes, por essa razão, compreende-se que estas ações antecedem o momento da consideração das expectativas. Sendo assim, o presente artigo compreende que a gestão de expectativas ocorre em duas etapas fundamentais: a fase de conhecimento das expectativas (identificar e coletar) e a fase de consideração das expectativas.

Com relação à identificação e coleta, as normas de auditoria não definem com clareza qual procedimento deve ser realizado primeiro ou se a identificação e a coleta possam ser sinônimas. Em razão disso, é possível que a identificação ocorra primeiro, como um filtro para a etapa da coleta das expectativas, como também a unidade de auditoria pode adotar a sistemática de coletar todas as informações sobre as partes interessadas e a partir disso identificar os 
principais stakeholders. No entanto, caso se compreenda que são ações que refletem o mesmo fim, não há como reconhecer a existência de mais uma fase ou etapa. Por isso, nesta pesquisa será considerado que ambos os procedimentos representam a mesma fase de conhecimento, mas que envolvem ações distintas e que podem ocorrer simultaneamente, sendo que sempre previamente ao momento da consideração das expectativas.

O IIA (2017) estabelece que o Auditor-Chefe deve identificar as expectativas dos gestores, conselho e demais partes interessadas, demonstrando o seu papel estratégico e a aproximação que possui com os stakeholders, sendo capaz de definir as partes consideradas chaves. Sendo assim, a identificação é a etapa de definição dos principais stakeholders (key stakeholders). Trata-se, portanto, de uma atividade de priorização para os trabalhos, ao se estabelecer as principais partes interessadas. Estas partes denominadas chaves são consideradas assim em virtude de sua ligação muito próxima com a auditoria interna, como por exemplo, conselhos, comitês e a alta gestão (IIA, 2019; PROTIVITI, 2016; PIPER, 2015).

A coleta é a forma pela qual a auditoria colhe as informações sobre as expectativas das partes interessadas. As normas de auditorias apontam que a coleta deve acontecer principalmente na elaboração do Plano de Auditoria Interna ou no planejamento de um trabalho, mas também pode ser realizado em atividades de consultoria, sempre de forma prévia ao início dos trabalhos (CGU, 2017a; IIA, 2017).

A consideração é o momento de análise das expectativas dos principais stakeholders realizado pela auditoria interna durante a execução dos trabalhos, no planejamento, na comunicação de resultados e na emissão de opinião (CGU, 2017a; IIA, 2017). Trata-se, portanto, de uma etapa crucial que permeia todas as atividades da auditoria interna, pois a finalidade é diminuir as diferenças de expectativas e para que isso ocorra, é necessário adotar a melhor abordagem para o atendimento das expectativas ou a mitigação de diferenças de expectativas. A Figura 01 demonstra as etapas da gestão de expectativas:

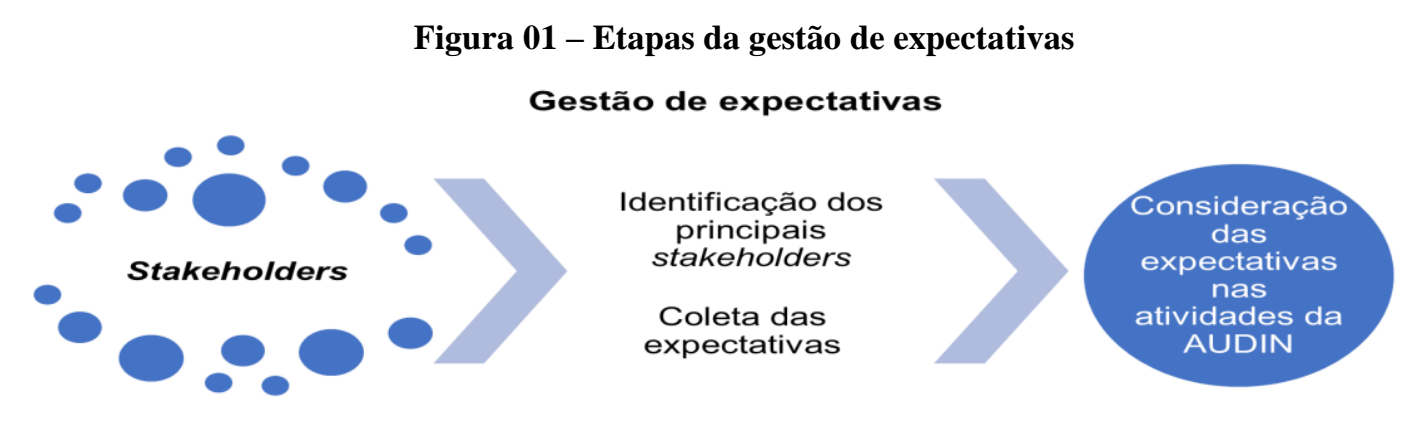

Fonte: Elaborado pelos Autores. 
A finalidade da gestão de expectativas na auditoria interna pode ser visualizada de duas formas: a) conhecer as expectativas das principais partes interessadas (IIA, 2012; PROTIVITI, 2016; PWC, 2017a); e b) buscar o atendimento das expectativas ou a mitigação das diferenças de expectativas (D'ONZA; LAMBOGLIA; VERONA, 2015; IBGC, 2018; ERASMUS; COETZEE, 2018).

Tendo em vista que o alinhamento aos objetivos estratégicos da organização é um indicador de maturidade da unidade de auditoria interna e a gestão de expectativas das partes interessadas pode assegurar maior efetividade à auditoria interna (ABDOLMOHAMMADI; D'ONZA; SARENS, 2016; ERASMUS; COETZEE, 2018), a literatura dedicada ao tema tem apontado algumas considerações sobre o assunto, descrevendo que o alinhamento estratégico requer uma postura da auditoria para demonstrar capacidade de resposta ágil às necessidades internas e externas, principalmente em ambientes problemáticos (PWC, 2017b). Para isso, é importante a habilidade de comunicação para transmitir mensagens à gestão e demais partes interessadas de maneira que possam compreender (D'ONZA; LAMBOGLIA; VERONA, 2015).

Além disso, como a unidade de auditoria interna foi desenhada para ser estratégica, ágil, informada, colaborativa e capacitada, a relação com a gestão e a habilidade de comunicação possuem o mesmo peso para as capacidades técnicas da auditoria (WEBSTER, 2016). Sobre isso, convém lembrar que Humprhey, Moizer e Turley (1992) demonstraram que a postura inadequada dos auditores na Inglaterra favoreceu a perpetuação das diferenças de expectativas.

O papel dos auditores na mitigação das diferenças de expectativas é essencial (PORTER; GOWTHORPE, 2004). Sendo assim, Webster (2016) demonstra a importância do chefe da unidade de auditoria interna na condução desse papel, descrevendo que este deve ser um líder com alta integridade; ter coragem; presença executiva; um forte entendimento do negócio; desejo de aprender; capacidade de gerenciar expectativas e influências; e ser um comunicador eficaz.

\section{METODOLOGIA}

Quanto aos objetivos, trata-se de uma pesquisa descritiva, pois procura observar, analisar e compreender fenômenos, sem a interferência do pesquisador (ANDRADE, 2002). No caso, busca-se compreender como é realizada a gestão de expectativas no âmbito da unidade de auditoria interna do IFRN. Além disso, também se trata de uma pesquisa exploratória. Considerando que o tema é pouco explorado, foi necessário realizar procedimentos para que o problema de pesquisa seja mais esclarecido. Sobre isso, Roussy e Perron (2018), em seu estudo, concluíram que pouco se sabe sobre as práticas em auditoria interna, sendo necessário pesquisas 
sobre essa questão, tendo em vista que os procedimentos quase não são documentados e compreendidos.

Quanto aos procedimentos, trata-se de uma pesquisa do tipo estudo de caso, pois o pesquisador busca concentrar esforços em um único objeto de estudo, com a finalidade de "aprofundar seus conhecimentos a respeito de determinado caso específico" (RAUPP; BEUREN, 2006, p. 84).

Tendo em vista que pouco se sabe sobre as práticas de auditoria interna, a presente pesquisa visa compreender como a unidade de auditoria interna do IFRN identifica, coleta e considera as expectativas da alta administração e demais partes interessadas.

Por outro lado, trata-se também de uma pesquisa documental, tendo em vista que utiliza material que não recebeu tratamento analítico (RAUPP; BEUREN, 2006). A exploração documental englobará os seguintes documentos: Normas de auditoria; Resoluções, Portarias; Instruções Normativas; Relatórios e documentos de auditoria; Manual de Auditoria; Regimentos; Estatutos; Plano de Desenvolvimento Institucional e Plano Anual de Auditoria Interna.

Quanto à abordagem do objeto, caracteriza-se como uma pesquisa qualitativa, pois busca se aprofundar no tema sem recorrer ao emprego de instrumentos estatísticos, ou seja, não há pretensão de quantificar ou medir no processo de análise do problema (RAUPP; BEUREN, 2006).

No tocante aos procedimentos de coleta de dados, adotou-se as seguintes técnicas de coleta de dados: a) pesquisa documental; e b) entrevista individual e grupo focal. No presente artigo, a pesquisa documental visa à obtenção de documentos necessários para a compreensão do problema de pesquisa, englobando as normas de auditoria aplicáveis à gestão de expectativas e documentos aplicáveis às atividades de planejamento, emissão de opinião e comunicação dos resultados na unidade de auditoria interna do IFRN. (MARCONI; LAKATOS, 2003).

Quanto à utilização da entrevista, o objetivo era obter informações dos participantes da pesquisa do que sabem, entendem, fizeram, fazem, ou pretendem fazer, além disso coletar os detalhamentos dos procedimentos já realizados e as percepções sobre o papel da auditoria quanto à gestão das expectativas.

A entrevista individual foi realizada com o Chefe da Auditoria Geral do IFRN e o grupo focal com os auditores. Essa separação se justifica pelo papel estratégico do chefe da unidade de auditoria interna na gestão de expectativas e atribuições distintas descritas na literatura e normas internacionais (IIA, 2017; WEBSTER, 2016).

No processo de discussão do grupo focal foi utilizado um roteiro semi estruturado de questões contendo 17 (dezessete) questões, Na entrevista individual, o roteiro também continha 17 questões, porém com algumas questões voltadas à atuação no âmbito da gestão da auditoria. 
Em ambos os casos, utilizou-se o tipo de entrevista por pautas, pois os questionamentos não eram rígidos e permitia flexibilidade na condução das discussões e inclusão de temas não previstos, que fossem relevantes para a pesquisa.

Sendo assim, as entrevistas focaram em questões abertas considerando as seguintes categorias de análise, conforme Quadro 01:

Quadro 01 - Categorias de análise

\begin{tabular}{|c|l|}
\hline $\begin{array}{c}\text { CATEGORIA DE } \\
\text { ANÁLISE }\end{array}$ & \multicolumn{1}{|c|}{ AUTORES } \\
\hline Planejamento da auditoria & $\begin{array}{l}\text { IBGC (2018); CGU (2017); IIA (2017); PWC (2017a), Abdolmohammadi, } \\
\text { D’Onza e Sarens (2016). }\end{array}$ \\
\hline Papel do Auditor-Chefe & $\begin{array}{l}\text { CGU (2017); IIA (2017); Webster (2016); D’Onza, Lamboglia e Verona } \\
\text { (2015). }\end{array}$ \\
\hline Atuação dos auditores & $\begin{array}{l}\text { IBGC (2018); IIA (2017); CGU (2017); Webster (2016); D’Onza; Lamboglia; } \\
\text { Verona, (2015); Humprhey, Moizer e Turley (1992) Porter; Gowthorpe } \\
\text { (2004). }\end{array}$ \\
\hline
\end{tabular}

Fonte: Elaborado pelos Autores.

No presente estudo, o tratamento de dados foi realizado por meio da análise de conteúdo, para descrever e interpretar o conteúdo dos dados obtidos nas duas entrevistas: a individual e o grupo focal (BARDIN, 1977). Além disso, foi realizada a análise documental, de todo o material, envolvendo documentos institucionais e normas.

A unidade de auditoria interna do IFRN, denominada de Auditoria Geral (AUDGE), atua como órgão auxiliar no Sistema de Controle Interno do Poder Executivo Federal e se sujeita à orientação normativa e supervisão técnica do órgão central do mencionado sistema (BRASIL, 2000; IFRN, 2014b).

A referida unidade tem a missão de adicionar valor à gestão; prestar apoio aos órgãos de controle e racionalizar as ações de controle. E as atividades da unidade se estendem por todos os serviços, programas, operações e controles existentes na referida instituição (IFRN, 2014b).

A unidade de auditoria interna do IFRN possui atualmente 17 (dezessete) auditores concursados, sendo um deles o Chefe da Auditoria Geral. A formação exigida para o cargo é curso de graduação em direito, ciências contábeis ou economia (BRASIL, 2005). No momento, 09 (nove) auditores possuem formação em ciências contábeis, 07 (sete) em direito e 01 (um) em economia (IFRN, 2019a).

Os auditores são vinculados administrativamente e tecnicamente à Auditoria Geral (Auditor-Chefe), que, por sua vez, está vinculada ao Conselho Superior (CONSUP), órgão máximo de deliberação da instituição (IFRN, 2014). A estrutura do setor é subdividida em três 
coordenações: Núcleo Reitoria (CONRE); Núcleo Seridó (CONSE) e Núcleo Alto Oeste (CONAO).

O critério de seleção dos participantes não envolveu amostragem probabilística, apenas uma seleção intencional em consonância com os objetivos do estudo (TRAD, 2009). Para o recrutamento, os auditores e o Chefe da Auditoria Geral foram convidados a participarem da pesquisa de forma voluntária. Quanto ao critério de exclusão, apenas o pesquisador integrante da AUDGE não foi considerado, a fim de manter a neutralidade e evitar ampliar as limitações da pesquisa. Diante disso, o número de participantes disponíveis para a pesquisa eram 16 (dezesseis) auditores, incluindo o Auditor-Chefe.

Para a seleção considerou-se apenas a voluntariedade dos participantes e a disponibilidade para a realização das entrevistas (individual e grupo focal). Ao final, 06 (seis) auditores aceitaram o convite e tinham disponibilidade para participar do grupo focal na data estipulada.

O Auditor-Chefe aceitou o convite e a data da entrevista foi agendada a fim de garantir a disponibilidade deste. Aos participantes, foi assegurado o anonimato na pesquisa e o sigilo das informações privadas, por meio da assinatura do Termo de Consentimento Livre e Esclarecido (TCLE).

\section{ANÁLISE E DISCUSSÃO DOS RESULTADOS}

A análise dos resultados está dividida, em duas seções, nas quais se busca abordar as duas etapas da gestão de expectativas, sendo a primeira seção dedica ao momento da coleta e identificação das expectativas e a segunda, a consideração das expectativas.

\subsection{Ciclo do planejamento e a coleta e identificação das expectativas}

De acordo com a pesquisa documental, o ciclo do planejamento das atividades das unidades de auditoria interna se inicia com o Plano Anual de Atividades de Auditoria Interna (PAINT) e se encerra com o Relatório Anual de Atividades de Auditoria Interna (RAINT). A Instrução Normativa CGU n ${ }^{\circ}$ 09, de 09 de outubro de 2018 é atualmente a norma que sistematiza a elaboração, comunicação e aprovação do PAINT e RAINT, em consonância com a Instrução Normativa CGU nº 03, de 09 de junho de 2017 (CGU, 2018a; CGU, 2017a).

O PAINT tem como principal finalidade definir os trabalhos que serão realizados no prazo definido no respectivo plano e é norteado pelos seguintes princípios: a autonomia técnica, a objetividade e a harmonização com as estratégias, os objetivos e os riscos da Unidade Auditada. (CGU, 2018a). 
Como se pode verificar, o planejamento da auditoria busca o alinhamento estratégico. Sendo assim, as expectativas da alta administração e demais partes interessadas são elementos importantes para a elaboração do PAINT. Essa previsão normativa estabelece, portanto, a necessidade de considerar as expectativas, o que pressupõe a necessidade prévia de identificar e coletar as expectativas dos key stakeholders (CGU, 2018a).

$\mathrm{Na}$ Auditoria Geral do IFRN, tanto os auditores como o Auditor-Chefe, por meio das entrevistas realizadas, informaram que o PAINT é subsidiado pelo Levantamento de Informações (GRUPO FOCAL, 2019; GESTOR, 2019). Trata-se de um instrumento utilizado para conhecer a organização e funcionamento da instituição, bem como avaliar a viabilidade de realização de auditorias (IFRN, 2018c).

Este trabalho de auditoria, portanto, tem como objetivo levantar informações com vistas a subsidiar o Plano Anual de Atividades de Auditoria Interna do exercício seguinte, por meio da apresentação de diagnósticos de determinados assuntos envolvendo a instituição e da sugestão de ações a serem previstas no PAINT (IFRN, 2019c).

Em outras palavras, é o meio utilizado para identificar e coletar a percepção dos key stakeholders e mapear os riscos institucionais a partir da visão destes, tendo em vista que a gestão de riscos ainda não foi implementada na instituição. Além disso, foi destacado que o ponto de partida do planejamento da auditoria interna é o Plano de Desenvolvimento Institucional (PDI), pois é a partir dele que há o alinhamento das atividades da auditoria com os objetivos e riscos institucionais (GESTOR, 2019).

No IFRN, o PDI é "o instrumento que apresenta a estratégia de atuação do IFRN, sendo a base para a construção dos planos anuais em todas as suas unidades" (IFRN, 2019b, p. 8). Sendo, portanto, o documento escrito e formal que define o planejamento estratégico da instituição.

De acordo com análise documental, verificou-se que a auditoria interna do IFRN realiza o levantamento de informações considerando o PDI vigente, para definir os key stakeholders e realizar a coleta das informações necessárias à elaboração do PAINT, dentre elas as expectativas das principais partes interessadas com relação à unidade de auditoria interna do IFRN (IFRN, 2019d).

Embora o atual PDI possua vigência de 2019 até 2026, o Levantamento de Informações é um trabalho realizado anualmente, pois considera possíveis alterações no plano durante o período de vigência, bem como as mudanças e ampliações das expectativas dos key stakeholders ao decorrer do período (IFRN, 2019b e IFRN, 2019d).

O Relatório de Levantamento de Informações do ano de 2019 (RLI) se baseou no Plano de Desenvolvimento Institucional - PDI 2019-2026. Neste PDI foi desenhado o Mapa estratégico do 
IFRN, o qual foi dividido em quatro faixas, sendo cada uma delas uma perspectiva do planejamento estratégico do IFRN, as quais são: Perspectiva de Estudantes e Sociedade; Perspectiva de Processos Acadêmicos; Perspectiva de Gestão e Infraestrutura; e Perspectiva de Orçamento (IFRN, 2019d).

Para o cumprimento dos objetivos estratégicos do IFRN, o PDI 2019-2026 elencou as iniciativas estratégicas, denominadas de "projetos estratégicos" e designou uma área responsável, ou seja, um setor responsável. Considerando que esse conjunto de projetos possui alto grau de contribuição para a estratégia institucional, a auditoria interna do IFRN definiu cada setor responsável descrito no mencionado PDI como key stakeholders.

Com a definição dos key stakeholders, o mencionado trabalho de auditoria realiza a coleta de informações, que abordam os seguintes temas: gestão de riscos, sugestão de temas de auditoria; e perspectiva dos gestores com relação à contribuição das auditorias e as expectativas sobre a auditoria interna do IFRN (IFRN, 2019d).

Com o recebimento das respostas, passa-se para a análise das informações coletadas. No tocante à percepção dos key stakeholders (gestores dos setores responsáveis pelos projetos estratégicos) sobre a contribuição das auditorias realizadas no respectivo setor e as expectativas em relação à auditoria interna, o RLI descreve que as respostas dos setores podem "conferir alguns parâmetros para saber se a unidade está conseguindo cumprir sua missão e principalmente verificar se a auditoria é percebida como agregadora de valor à instituição" (IFRN, 2019d, p. 5).

A partir da análise documental, foi possível verificar que além de demonstrar as expectativas dos setores respondentes, o mencionado relatório de auditoria informa que a previsão normativa não impõe à unidade de auditoria interna a obrigação de atender as expectativas do cliente. Por outro lado, esclarece que o RT pretende que os auditores tomem conhecimento e examinem as expectativas das partes interessadas durante toda a execução dos trabalhos, a fim de atingir o alinhamento entre unidade de auditoria e a gestão da instituição, eliminando ou mitigando possíveis diferenças de expectativas em auditoria (IFRN, 2019d).

Sendo assim, com a conclusão do RLI, este documento é encaminhado ao Chefe da Auditoria Geral do IFRN. O PAINT, então, começa a ser elaborado, considerando as informações coletadas.

Convém destacar que, embora o levantamento de informações apresente sugestões de temas de auditoria com base na avaliação de riscos, a Instrução Normativa CGU no 09/2018 permite, desde que de forma justificada, a inclusão de outros trabalhos "em função de obrigação normativa, por solicitação da alta administração ou por outros motivos que não a avaliação de riscos" (CGU, 2018a, p. 2). 
Após confecção do documento pela unidade de auditoria interna do IFRN, a proposta do PAINT e eventuais alterações precisam ser encaminhadas à CGU, "de forma a possibilitar a harmonização do planejamento, racionalizar a utilização de recursos e evitar a sobreposição de trabalhos" (CGU, 2018a, p. 3).

Além do envio da proposta à CGU no prazo definido na Instrução Normativa CGU $\mathrm{n}^{\circ}$ 09/2018, o PAINT deve também ser aprovado pelo conselho de administração ou órgão equivalente, que no caso do IFRN é o Conselho Superior (CONSUP) (IFRN, 2009). Com a aprovação do PAINT, este deve ser encaminhado à CGU "até o último dia útil do mês de fevereiro do ano da execução para exercício da supervisão técnica” (CGU, 2018a, p. 4).

Com o PAINT aprovado, o Chefe da Auditoria Geral emite as Ordens de Serviços (OS) para as equipes de auditores executarem as ações previstas no planejamento. Assim, a auditoria interna do IFRN inicia a execução dos trabalhos, determinando o escopo, amostragem, alcance dos procedimentos, as técnicas apropriadas, bem como emitindo documentos para o andamento das auditorias em execução (IFRN, 2014b).

Após a conclusão dos trabalhos, os auditores condensam todos os achados e evidências dos trabalhos, formulam as recomendações e emitem a opinião sobre o objeto auditado nos relatórios de auditoria (IFRN, 2014b; IFRN, 2018c). Com a comunicação dos resultados dos trabalhos, por meio dos relatórios de auditoria, a equipe de auditores passa a realizar o monitoramento, que é a fase em que se emitem o Plano de Providência Permanente (PPP), para o acompanhamento da implementação das recomendações emitidas nos relatórios (GRUPO FOCAL, 2019). O resultado desse tipo de trabalho é formalizado em um relatório de monitoramento (IFRN, 2014b; IFRN, 2018c).

Ao final do período do Plano Anual de Atividades de Auditoria Interna, é realizada a confecção do Relatório Anual de Atividades de Auditoria Interna (RAINT), que informa "sobre a execução do PAINT e a análise dos resultados decorrentes dos trabalhos de auditoria" (CGU, 2018a, p. 5).

Após a confecção do documento, a auditoria interna comunica o RAINT ao Conselho Superior e disponibiliza à CGU, "no prazo de 90 dias após o término da vigência do PAINT para exercício da supervisão técnica" (CGU, 2018a, p. 6).

O resumo dos procedimentos realizados pela AUDGE desde a elaboração até a conclusão do planejamento das atividades pode ser verificado na Figura 02: 
Figura 02 - Procedimentos da auditoria interna

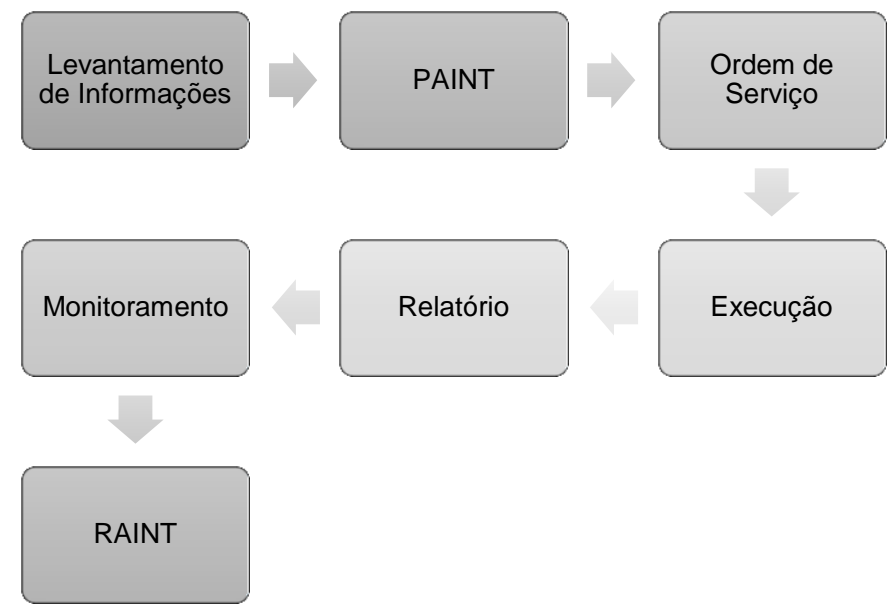

Fonte: Elaborado pelos Autores.

De acordo com a análise documental, verificou-se que, embora o plano de auditoria seja elaborado para que haja seu pleno cumprimento, é possível que as ações planejadas não sejam concluídas ou realizadas, bem como exista a possibilidade de ocorrer a inclusão de trabalhos de auditoria não previstos no PAINT. Na AUDGE, este trabalho é denominado de auditoria especial (IFRN, 2014b; IFRN, 2018c). De acordo com a Instrução Normativa CGU nº 03/2017, planejamento da UAIG deve ser flexível, considerando a possibilidade de mudanças no contexto organizacional da Unidade Auditada (CGU, 2017a, p. 17).

As auditorias especiais são realizadas durante a execução do PAINT. Ou seja, seguem a sequência dos trabalhos ordinários a partir da emissão da Ordem de Serviço. Por se tratarem de ações não previstas no PAINT, a unidade de auditoria deve comunicar à alta administração ou conselho, as mudanças relevantes que impactaram o planejamento inicial (CGU, 2017a).

Ao final do ciclo do planejamento, o RAINT deve conter informações sobre o quantitativo de ações não concluídas, não realizadas e não previstas no PAINT, bem como a descrição dos fatos que provocaram essas situações (CGU, 2018a).

4.2 Operacionalização das atividades de auditoria e a consideração das expectativas.

No âmbito do SCIPEF, as etapas da operacionalização dos trabalhos da auditoria preveem a necessidade de considerar as expectativas do cliente, tais como no planejamento, execução de auditoria, emissão de opinião e na comunicação dos resultados. (CGU, 2017a). Em razão disso, neste tópico será dado enfoque à atuação dos auditores, bem como na atuação do Auditor-Chefe na gestão da respectiva unidade. 


\subsubsection{Atuação dos auditores}

No IFRN, verificou-se que, por meio dos documentos analisados, a fase de conhecimento das expectativas (identificação e coleta) possui uma rotina de procedimentos definida. A utilização do Levantamento de Informações como subsídio ao PAINT promove a busca pelo alinhamento estratégico via PDI, define as principais partes interessadas e coleta suas expectativas (IFRN, 2019d).

O Relatório do Levantamento de Informações (RLI) apresenta dados envolvendo gestão de riscos; sugestões de trabalhos de auditoria para o PAINT do exercício seguinte; informações sobre a atuação da auditoria interna do IFRN na perspectiva dos gestores; e expectativas em relação à Auditoria Geral (IFRN, 2019d).

O RLI, em 2019, demonstrou que as principais partes interessadas esperam mais da Auditoria Geral do que estão recebendo atualmente (melhoria dos controles internos, processos e padronização de procedimentos) (IFRN, 2019). A descrição das novas expectativas dos stakeholders contidas no referido relatório estão condizentes com as discussões na literatura dedicada à auditoria interna, em especial aos temas sobre diferenças de expectativas em auditoria e gestão de expectativas, conforme se verifica no Quadro 02:

\section{Quadro 02 - Relação das expectativas dos gestores com as discussões na literatura}

\begin{tabular}{|c|c|}
\hline EXPECTATIVAS & AUTORES \\
\hline $\begin{array}{c}\text { Mudança de postura e abordagem da auditoria } \\
\text { Participação da unidade de auditoria interna na } \\
\text { implementação da gestão de riscos }\end{array}$ & $\begin{array}{c}\text { PWC (2017b); Marçola (2011); Attie } \\
\text { (2012); Faustino; Nascimento; Costa (2016) }\end{array}$ \\
\hline $\begin{array}{c}\text { Atuação da auditoria na implementação da } \\
\text { governança de TI }\end{array}$ & IBGC (2018); PWC (2017d) \\
\hline $\begin{array}{c}\text { Utilização da auditoria interna na qualificação e } \\
\text { capacitação de servidores }\end{array}$ & $\begin{array}{c}\text { Sarens e Beelde (2006); Burton } \text { et al. } \text { (2015); } \\
\text { Christ } \text { et al. } \text { (2015). }\end{array}$ \\
\hline
\end{tabular}

Fonte: Elaborado pelos Autores.

De acordo com a análise documental, verificou-se que o planejamento da auditoria no período de 2016 até 2019 não previu ações envolvendo a implantação da gestão de riscos. No entanto, quanto à governança em Tecnologia da Informação (TI), foram previstas três atividades de auditoria no mesmo período (IFRN, 2017b; IFRN, 2018a; IFRN, 2018b; IFRN, 2019a)

As outras duas expectativas não envolvem trabalhos de auditoria convencional. No caso da utilização dos auditores para capacitação dos servidores, o Manual de Orientações Técnicas da Atividade de Auditoria Interna Governamental do Poder Executivo Federal define essa atividade como um tipo de serviço de consultoria, a qual pode ser realizada na forma de treinamento ou facilitação, desde que não haja prejuízo à autonomia técnica e objetividade (CGU, 2017b). 
Os participantes do grupo focal descreveram que já foram realizadas ações de capacitação por parte da Auditoria Geral, porém demonstraram incerteza sobre a adequação dessa atividade às normas e evidenciaram a possibilidade de surgimento de interferências aos trabalhos de avaliação (GRUPO FOCAL, 2019).

Já a expectativa envolvendo a mudança de postura e abordagem da auditoria diz respeito exclusivamente à atuação dos auditores. Essa situação foi constatada pelo Chefe da Auditoria Geral, no momento da revisão dos relatórios, quando orienta os auditores a considerarem a mudança de abordagem e postura na condução dos trabalhos, a fim de garantir a isenção do julgamento, como também afastar a imagem coercitiva ou policialesca da auditoria, a qual ainda é percebida pelos auditados (GESTOR, 2019).

A identificação e coleta dessa expectativa demonstram que as principais partes interessadas ainda esperam uma mudança de postura e abordagem por parte dos auditores. Quanto as outras expectativas, ainda que a AUDGE tenha promovido cursos de capacitação e ações de auditoria na área de TI, os key stakeholders esperam mais da auditoria interna do IFRN.

O momento da consideração é a etapa crucial da gestão de expectativas, nela é realizada a análise das expectativas das partes interessadas para que a auditoria interna adote a melhor abordagem para satisfazê-las ou para mitigar possíveis diferenças de expectativas em auditoria.

A consideração das expectativas ocorre durante todo o ciclo de atividades da UAIG (IIA, 2017; CGU, 2017a). De acordo com as normas de auditoria, é possível verificar três momentos essenciais para a gestão de expectativas: o planejamento, a emissão de opinião e a comunicação dos resultados dos trabalhos.

Na elaboração do planejamento, a Auditoria Geral considera as expectativas identificadas e coletadas no Levantamento de Informações para a seleção de trabalhos de auditoria alinhados aos riscos, objetivos e prioridades institucionais. Nas demais etapas, ocorre com mais profundidade a análise dessas expectativas, principalmente pelos auditores.

Os auditores analisam os achados de auditoria e comunicam os resultados dos trabalhos, por meio dos relatórios. Nesse momento, a consideração de expectativas não possui uma rotina de procedimentos bem definida pelo Auditor-Chefe, pois este prefere garantir a autonomia dos auditores, focando na supervisão dos trabalhos, em especial na revisão dos relatórios (GESTOR, 2019).

Por conta dessa falta de padronização ou estabelecimento prévio de procedimentos para a consideração das expectativas, os relatos dos auditores no grupo focal evidenciaram casos em que se verificaram fragilidades quanto à: análise deficiente dos auditores; presença de interferências ou pressões, em especial nos casos dos auditores dos núcleos do interior (CONAO e CONSE); 
comunicação interna falha; e relação conflituosa entre auditor e auditado (GRUPO FOCAL, 2019).

A fragilidade na análise das expectativas foi demonstrada por auditores, nos seguintes aspectos: dificuldades para redigir a opinião conforme expectativas dos gestores; receios de reações indesejadas; e limitação da abrangência das recomendações (GRUPO FOCAL, 2019).

No tocante às interferências ou pressões, destacou-se que a compreensão da atividade da auditoria interna é muitas vezes desvirtuada, pois algumas partes interessadas entendem que os trabalhos dos auditores se confundem com atos próprios de gestores, principalmente na situação dos auditores que estão lotados em campus e não na Reitoria do IFRN (GRUPO FOCAL, 2019).

A comunicação dentro da AUDGE foi apresentada como falha, principalmente, quando os auditores são consultados sobre os resultados dos trabalhos realizados por outra equipe ou outro auditor (GRUPO FOCAL, 2019). Possibilitando a frustração de expectativas quanto à capacidade de resposta ágil da auditoria interna do IFRN.

Quanto à relação conflituosa entre auditor e auditado, os participantes informaram inicialmente que as relações entre Auditoria Geral e alta administração têm se aperfeiçoado e buscado o alinhamento, no entanto, a relação com as demais partes interessadas apresenta dificuldade em assimilar ou compreender o papel e responsabilidade da auditoria interna, o que acaba provocando expectativas desarrazoadas (GRUPO FOCAL, 2019).

Em todo caso, as fragilidades indicadas afetam a consideração das expectativas, ou seja, a análise feita pelos auditores. A relação conflituosa pode interferir na isenção do julgamento do auditor, acarretando uma possível abordagem insuficiente ou inadequada para satisfazer a expectativa dos stakeholders ou mitigar as diferenças de expectativas.

O desconhecimento de trabalhos realizados por outras equipes pode provocar uma lacuna de informação que poderia auxiliar na consideração de expectativas por outra equipe ou auditor, ou ainda provocar a frustração de expectativas por falta de análise, em razão da carência de dados.

As interferências ou pressões também podem provocar a ampliação das diferenças de expectativas. A deficiência no desempenho dos auditores, de igual forma, pode promover o desalinhamento de expectativas entre as partes. Por conta disso, o Chefe da Auditoria Geral revisa os relatórios das equipes de auditores para verificar, principalmente, a adequação da abordagem e postura dos auditores (GESTOR, 2019).

Embora os auditores tenham relatado exemplos de auditorias que buscaram corresponder às expectativas (GRUPO FOCAL, 2019), os casos de fragilidades demonstram a necessidade de 
se estabelecer uma rotina de procedimentos para orientar os auditores no gerenciamento das expectativas, a fim de evitar as inconsistências na análise das expectativas das partes interessadas.

Diante disso, convém destacar que o RLI, inclusive, recomenda o treinamento dos auditores para realizarem a gestão de expectativas no âmbito da Auditoria Geral, especialmente para a etapa da consideração das expectativas dos gestores no planejamento, comunicação dos resultados e emissão de opinião (IFRN, 2019d).

\subsubsection{Papel do auditor-chefe}

No âmbito do SCIPEF, o responsável pelo mais alto nível de gestão nas Auditorias Internas singulares (Audin) é denominado Auditor-Chefe (CGU, 2017a). As normas do IIA (2017), por outro lado, o denomina de Executivo Chefe de Auditoria (Chief Audit Executive CAE). No IFRN, esse cargo também possui a nomenclatura de Chefe da Auditoria Geral (IFRN, 2014b).

As normas de auditoria estabelecem e definem o papel estratégico e a responsabilidade do gestor da unidade de auditoria interna para satisfazer as expectativas do cliente ou mitigar das diferenças de expectativas em auditoria. Após a coleta e análise dos dados, verificou-se que o papel do Chefe da Auditoria Geral do IFRN na gestão de expectativas envolve prioritariamente duas responsabilidades: a comunicação com a alta administração e a supervisão dos trabalhos de auditoria.

A comunicação do Auditor-Chefe envolve a interação direta e reporte à alta administração, a busca pelo alinhamento estratégico e mitigação de diferenças de expectativas em auditoria. Já a supervisão abrange atividades de operacionalização das atividades realizadas pela Auditoria Geral do IFRN que visam o cumprimento dos objetivos traçados no planejamento da auditoria, a verificação da qualidade dos trabalhos e assegurar a autonomia técnica e objetividade dos trabalhos.

A comunicação realizada pelo Auditor-Chefe por meio da interação direta diz respeito ao acesso irrestrito do Chefe da Auditoria Geral ao conselho e à alta administração (IIA, 2017; CGU, 2017a). Já o reporte é a comunicação formal e periódica. Ou seja, é o meio adequado que o Auditor-Chefe pode divulgar e solicitar providências ao Conselho quanto às ameaças à autonomia técnica e objetividade (IIA, 2017; CGU, 2017a). As normas do IIA (2017) estabelecem alguns exemplos de reporte, tais como: a aprovação do estatuto e planejamento da auditoria interna.

O participante 01 do grupo focal descreveu o papel relevante desempenhado pelo Chefe da Auditoria Geral, pois, ao se comunicar com a alta gestão, pode compreender melhor as necessidades e os objetivos da instituição (GRUPO FOCAL, 2019). 
Em razão disso, o alinhamento estratégico é promovido pelo Auditor-Chefe na medida em que este se comunica com as principais partes interessadas e busca compreender os riscos e objetivos da instituição. Com isso, haverá o aumento da percepção e o valor da auditoria interna dentro da instituição (GRANT-THORTON, 2015).

De acordo com Piper (2015), a auditoria interna no setor público possui uma base ampla de partes interessadas, com expectativas a serem conhecidas e correspondidas pelos auditores. Porém, nem sempre estes possuem condições de consultar as necessidades dos stakeholders.

Tendo em vista que a atuação da auditoria se estende por toda a instituição, o IBGC (2018) esclarece que são muitas instâncias e setores com os quais a unidade de auditoria interna se relaciona. Por conta disso, a comunicação com as partes interessadas pode ser facilitada por meio da atuação do Auditor-Chefe, que deve possuir conhecimento da instituição e equilibrar as expectativas e necessidades dos principais interessados (WEBSTER, 2015).

Nessa mesma linha, o Auditor-Chefe pode promover a mitigação das diferenças de expectativas, por meio do contato direto e irrestrito à Alta gestão, bem como por meio do reporte. Com o aumento e mudanças nas expectativas em torno da auditoria interna (PIPER, 2015; CIIA, 2018), o processo de comunicação entre a UAIG e a alta administração precisa ser eficaz (CGU, 2017a; CIIA, 2018).

Como consequência, é necessário construir um bom relacionamento com as partes interessadas e esse esforço envolve o gerenciamento de expectativas relacionadas ao papel da auditoria (IBGC, 2018). Ao identificar os principais stakeholders e ao considerar as expectativas destes no plano de auditoria, o reporte do Auditor-Chefe à alta administração solicitando a aprovação do planejamento, bem como demonstrando o desempenho da UAIG pode promover o alinhamento de expectativas entre as partes, por exemplo.

Quanto ao papel da supervisão do Auditor-Chefe, essa atribuição visa assegurar o cumprimento dos objetivos, a qualidade dos trabalhos e evitar possíveis interferências aos julgamentos profissionais (ameaças à independência e objetividade) (CGU, 2017a).

Durante a execução dos trabalhos previstos no PAINT, o Auditor-Chefe tem a responsabilidade pela supervisão dos trabalhos, mas possui permissão normativa para delegar a integrantes do corpo funcional da unidade de auditoria interna (CGU, 2017a). A supervisão é exercida desde o planejamento até a fase do monitoramento das recomendações (CGU, 2017a), e inclui, dentre outras atribuições, assegurar a proficiência e fornecer instruções para a equipe; conferir a qualidade da divulgação dos resultados; garantir que os objetivos dos trabalhos de auditoria sejam atingidos (CGU, 2017a). 
No IFRN, verificou-se que a atuação do Chefe da Auditoria Geral promoveu mudanças na forma como a auditoria se comunica e se articula na Instituição. Os participantes do grupo focal relataram que o Auditor-Chefe participa de reuniões com a alta administração e se comunica com as partes auditadas. Por meio dessa comunicação, os auditores demonstraram que a relação entre a auditoria interna do IFRN e a alta administração melhorou, bem como o planejamento da AUDGE está buscando o alinhamento estratégico (GRUPO FOCAL, 2019).

A utilização do Levantamento de Informações para subsidiar o PAINT é a medida que o Chefe da Auditoria Geral utiliza para elaborar o planejamento alinhado aos riscos e objetivos institucionais, bem como o meio de identificação e coleta das expectativas dos principais stakeholders (GESTOR, 2019; IFRN, 2019d; IFRN, 2018b).

Na perspectiva dos auditores, o Auditor-Chefe contribui para os trabalhos de auditoria por meio dos resultados advindos da construção de um bom relacionamento com a alta administração (interação e reporte) e da comunicação prévia com os auditados (GRUPO FOCAL, 2019). De acordo com a análise documental, o reporte ao Conselho Superior implicou na: reestruturação funcional da Auditoria Geral em 2014; aprovação do regimento da auditoria interna do IFRN em 2014; análise e aprovação anual do PAINT; aprovação de alteração no PAINT em 2017; e análise e aprovação anual do RAINT (IFRN, 2014a; IFRN, 2014b, IFRN, 2017a).

Além disso, a participação do Auditor-Chefe nas reuniões com a alta administração e demais gestores reforça a importância do papel da AUDGE na instituição, bem como proporciona o compartilhamento de informações relevantes da gestão com os auditores (GRUPO FOCAL, 2019).

Durante a supervisão dos trabalhos, o Auditor-Chefe exemplificou como orienta os auditores principalmente no momento da revisão dos relatórios, buscando verificar se a análise foi bem fundamentada, se há margem para má interpretação (narrativa agressiva ou tendenciosa), se houve falta de objetividade nos trabalhos e se os objetivos foram alcançados (GESTOR, 2019). E demonstrou que, embora prefira, de forma geral, não interferir na autonomia do auditor, busca orientar a equipe de auditores a fim de assegurar que a opinião da auditoria seja emitida de forma isenta. Além disso, informou que verifica se o programa de trabalho (denominado de programa de auditoria na AUDGE) foi cumprido e realiza a confirmação de que os achados de auditoria são pertinentes e adequados para sustentar as constatações e recomendações nos relatórios (GESTOR, 2019).

Não obstante os relatos de melhorias que ocorreram por meio do papel do Auditor-Chefe, verificou-se fragilidades relacionadas à gestão de expectativas na AUDGE. Considerando o papel e responsabilidade do Chefe da Auditoria Geral perante esses casos, a situação merece atenção e medidas por parte do referido gestor. 
Conforme relatado pelos participantes do grupo focal, há evidências de fragilidades que podem colocar em risco a efetividade e qualidade dos trabalhos, a imparcialidade dos julgamentos profissionais e a mitigação das diferenças de expectativas (GRUPO FOCAL, 2019), conforme se verifica no Quadro 03:

Quadro 03 - Relação de fragilidades e o Papel do Auditor-Chefe

\begin{tabular}{|c|c|c|}
\hline FRAGILIDADES & DADOS & $\begin{array}{l}\text { PAPEL DO AUDITOR- } \\
\text { CHEFE }\end{array}$ \\
\hline $\begin{array}{l}\text { Má compreensão do } \\
\text { papel e } \\
\text { responsabilidade da } \\
\text { auditoria pelas demais } \\
\text { partes interessadas }\end{array}$ & $\begin{array}{l}\text { Os auditores relataram que as demais partes } \\
\text { interessadas (demais servidores e gestores de } \\
\text { nível operacional) ainda não compreendem o } \\
\text { papel e responsabilidade da auditoria interna do } \\
\text { IFRN. }\end{array}$ & $\begin{array}{l}\text { Esclarecer qual o papel e quais } \\
\text { os serviços a auditoria interna } \\
\text { está habilitada ou não a } \\
\text { prestar. } \\
\text { Fundamento: (CGU, 2017a; } \\
\text { IIA, 2017) }\end{array}$ \\
\hline $\begin{array}{lr}\text { Falhas quanto } & \text { à } \\
\text { interpretação, } & \\
\text { extensão } & \text { e } \\
\text { apresentação } & \text { dos } \\
\text { relatórios } & \end{array}$ & $\begin{array}{l}\text { Há uma indefinição na forma de comunicação dos } \\
\text { resultados, ainda que algumas medidas tenham } \\
\text { sido tomadas, os auditores não entraram em } \\
\text { consenso para estabelecer uma rotina para } \\
\text { aprimorar a divulgação, a leitura e o tamanho dos } \\
\text { relatórios. }\end{array}$ & $\begin{array}{l}\text { Estabelecer a forma de } \\
\text { comunicação dos resultados. } \\
\text { Fundamento: (CGU, 2017a; } \\
\text { IIA, 2017) }\end{array}$ \\
\hline $\begin{array}{l}\text { Problemas de } \\
\text { comunicação interna }\end{array}$ & $\begin{array}{l}\text { Os auditores não possuem conhecimento dos } \\
\text { resultados dos trabalhos executados por outras } \\
\text { equipes, o que pode provocar a frustração de } \\
\text { expectativas quanto à agilidade nas repostas da } \\
\text { auditoria. }\end{array}$ & $\begin{array}{l}\text { Aprimorar a forma de } \\
\text { comunicação interna. } \\
\text { Fundamento: (CGU, 2017a; } \\
\text { IIA, 2017) }\end{array}$ \\
\hline $\begin{array}{lr}\text { Dificuldades } & \text { para } \\
\text { corresponder } & \text { às } \\
\text { expectativas } & \text { na } \\
\text { emissão de opinião } & \end{array}$ & $\begin{array}{l}\text { Dificuldade para satisfazer as expectativas das } \\
\text { partes interessadas, em virtude da insegurança de } \\
\text { alguns auditores, expectativas desarrazoadas e } \\
\text { falta de procedimento que defina a melhor } \\
\text { abordagem para cada expectativa. }\end{array}$ & $\begin{array}{l}\text { Capacitação para os auditores } \\
\text { e definir uma rotina de } \\
\text { procedimentos para o } \\
\text { momento da consideração das } \\
\text { expectativas. } \\
\begin{array}{l}\text { Fundamento: (CGU, 2017; } \\
\text { IIA, 2017a) }\end{array}\end{array}$ \\
\hline $\begin{array}{l}\text { Ameaças à autonomia } \\
\text { técnica e objetividade }\end{array}$ & $\begin{array}{l}\text { Há relatos de interferências envolvendo } \\
\text { subordinação e expectativas desarrazoadas (tais } \\
\text { como: solicitação de atividades próprias da } \\
\text { Administração) }\end{array}$ & $\begin{array}{l}\text { Reporte à alta administração. } \\
\text { Fundamento: (CGU, 2017a; } \\
\text { IIA, 2017) }\end{array}$ \\
\hline $\begin{array}{l}\text { Número excessivo de } \\
\text { recomendações não } \\
\text { atendidas }\end{array}$ & $\begin{array}{l}\text { Um número excessivo de recomendações não } \\
\text { atendidas pelos auditados, levanta a suspeita de } \\
\text { falta de suporte gerencial e também demonstra } \\
\text { possível falta de clareza, objetividade e } \\
\text { viabilidade das recomendações. }\end{array}$ & $\begin{array}{l}\text { Reporte à alta administração e } \\
\text { revisão dos relatórios. } \\
\text { Fundamento: (CGU, 2017a; } \\
\text { IIA, 2017) }\end{array}$ \\
\hline
\end{tabular}

Fonte: Elaborado pelos Autores.

O Quadro 03 apresenta os dados referentes às fragilidades elencadas e o papel do AuditorChefe da AUDGE diante de cada ponto de melhoria. As medidas descritas estão amparadas nas normas do IIA (2017) e no RT (CGU, 2017a).

No tocante à comunicação, o Chefe da Auditoria Geral demonstrou que a unidade de auditoria interna utiliza vários instrumentos, tais como: memorandos, solicitação de auditoria; nota de auditoria; e relatórios. Além disso, realiza a interação direta e reporte com a alta 
administração e demais gestores, por meio de comunicação formal, informal e participação em reuniões de conselhos (GESTOR, 2019).

Com a adoção do processo eletrônico na instituição, entende que a comunicação se tornou mais ágil e otimizada, não vislumbrando problemas graves ou fragilidades no processo de comunicação entre auditoria e auditado (GESTOR, 2019).

No tocante à supervisão, o Chefe da Auditoria Geral demonstrou preocupação quanto à abordagem e postura dos auditores, tendo em vista a relação conflituosa entre auditor e auditado. Em razão disso, busca orientar os auditores para que sejam objetivos, evitando potencializar ou desmerecer achados de auditorias durante os trabalhos (GESTOR, 2019).

Por outro lado, o Chefe da Auditoria Geral compreende que as expectativas dos key stakeholders não podem ser sempre satisfeitas, porque elas podem interferir na autonomia técnica da UAIG e na objetividade dos auditores. Sendo, portanto, desarrazoado considerá-las sempre (GESTOR, 2019).

Assim, o Chefe da Auditoria Geral entende que a interferência da expectativa é possível na comunicação, seja com a alta administração ou no momento da divulgação dos resultados, mas não pode interferir na execução dos trabalhos, especialmente no momento da emissão de opinião (GESTOR, 2019).

Pelo o exposto, o Auditor-Chefe evidencia que as diferenças de expectativas em auditoria ainda estão presentes no âmbito da instituição estudada. No entanto, ao se preocupar com a relação conflituosa e sensível entre auditores e auditados, o Chefe da Auditoria Geral acaba priorizando a consideração das expectativas ao processo de comunicação (de resultados e com a alta administração), em detrimento do momento da emissão de opinião.

\section{CONSIDERAÇÕES FINAIS}

O presente artigo buscou compreender como é realizada a gestão de expectativas no âmbito da unidade de auditoria interna do IFRN. Após a coleta e tratamento dos dados, buscou-se analisar o objeto de pesquisa considerando as duas etapas da gestão de expectativas, a saber: a fase de conhecimento (identificação e coleta) e a fase de consideração das expectativas.

Os resultados demonstram que a fase de conhecimento possui uma rotina de procedimentos pré-definida na AUDGE. Por meio do alinhamento ao Plano de Desenvolvimento Institucional vigente, o trabalho de auditoria, denominado de Levantamento de Informações, seleciona as principais partes interessadas (key stakeholders) e coleta as expectativas destes. Ao final, o resultado desse trabalho é registrado em Relatório de Auditoria, que subsidiará a elaboração do PAINT do exercício seguinte. 
$\mathrm{Na}$ fase da consideração de expectativas, verificou-se que a AUDGE não possui uma rotina de procedimentos para orientar os auditores nesta etapa. Em virtude disso, constataram-se fragilidades que podem interferir na efetividade e qualidade dos trabalhos, na imparcialidade dos julgamentos profissionais e na mitigação das diferenças de expectativas. Isto significa que a análise das expectativas das principais partes interessadas merece atenção.

A verificação da percepção do Auditor-Chefe e dos auditores quanto à gestão de expectativas na Auditoria Geral, evidenciou a existência de fragilidades que envolvem principalmente a comunicação de resultados e a emissão de opinião. No tocante ao papel do Chefe da Auditoria Geral, verificou-se que, por conta da realidade institucional, este prioriza a consideração das expectativas ao processo de comunicação (de resultados e com a alta administração) em detrimento da emissão de opinião.

Contudo, a existência de fragilidades na etapa de consideração eleva a importância de se estabelecer procedimentos para orientar a análise das expectativas das principais partes interessadas, considerando que o cenário apontado na literatura evidencia o surgimento de novas expectativas e a ampliação destas em torno da auditoria interna

Sobre isso, as normas aplicáveis à gestão de expectativas estabelecem a responsabilidade do Auditor-Chefe para a comunicação com a alta administração, por meio da interação direta e reporte, e a supervisão dos trabalhos, a fim de assegurar a qualidade dos trabalhos, o alcance dos objetivos e a isenção dos julgamentos técnicos. Dessa forma, as fragilidades devem ser gerenciadas pelo Chefe da Auditoria Geral.

Além disso, convém demonstrar que o presente artigo possui algumas limitações. A primeira diz respeito à abordagem da análise do objeto (gestão de expectativas na auditoria interna do IFRN), voltada exclusivamente sob a perspectiva dos auditores e do Auditor-Chefe, sem considerar a perspectiva das principais partes interessadas (key stakeholders). A segunda limitação está relacionada a utilização do grupo focal, que pode apresentar algumas limitações, porém foram tomadas algumas medidas para mitigá-las ou para evitar a ampliação delas.

No tocante à recomendação para futuras pesquisas, sugere-se a análise da gestão de expectativas, adotando a abordagem que compare a percepção dos auditores e dos key stakeholders. Além disso, considerando que a literatura descreve que pouco se sabe sobre os procedimentos das auditorias, recomenda-se, ainda, para futuras pesquisas, a aplicação de pesquisas em outras unidades de auditoria interna, utilizando o mesmo método, para que seja possível validar o esquema proposto. 


\section{REFERÊNCIAS}

ABDOLMOHAMMADI, Mohammad; D’ONZA, Giuseppe; SARENS, Gerrit. Benchmarking de Maturidade da Auditoria Interna - Um Olhar de Alto Nível Sobre o Planejamento e Processos de Auditoria do Mundo. IIARF, 2016

ALZEBAN, Abdulaziz; GWILLIAM, David. Factors affecting the internal audit effectiveness: A survey of the Saudi public sector. Journal of International Accounting, Auditing and Taxation, v. 23, n. 2, p. 74-86, 2014.

ANDRADE, Maria Margarida de. Como preparar trabalhos para cursos de pós-graduação: noções práticas. 5 ed., São Paulo: Atlas, 2002.

ATTIE, William. Auditoria Interna. $3^{\mathrm{a}}$ ed., $4^{\mathrm{a}}$ reimpr. São Paulo: Atlas, 2012.

BARDIN, Laurence. Análise de Conteúdo. Lisboa: Edições 70, 1977.

BOSNJAK, Jelena. Strategic Planning in Correlation with Internal Audit. European Project Management Journal, v.9, n.2, 2019.

BRASIL. Decreto n ${ }^{\text {o } 3591, ~ d e ~} 06$ de setembro de 2000. Dispõe sobre o Sistema de Controle Interno do Poder Executivo Federal e dá outras providências. Disponível em: http://www.planalto.gov.br/ccivil_03/decreto/D3591.htm Acesso em: 05 de maio de 2020.

BRASIL. Lei no 11.091, de 12 de janeiro de 2005. Dispõe sobre a estruturação do Plano de Carreira dos Cargos Técnico-Administrativos em Educação, no âmbito das Instituições Federais de Ensino vinculadas ao Ministério da Educação, e dá outras providências. Disponível em: http://www.planalto.gov.br/ccivil_03/_ato2004-

2006/2005/lei/L11091compilado.htm Acesso em: 09 de agosto de 2019.

BURTON, F. Greg et al. The effects of using the internal audit function as a management training ground or as a consulting services provider in enhancing the recruitment of internal auditors. Accounting Horizons, v. 29, n. 1, p. 115-140, 2015.

CGU. Instrução Normativa nº 03, de 09 de junho de 2017. Aprova o Referencial Técnico da Atividade de Auditoria Interna Governamental do Poder Executivo Federal. Diário Oficial da União, Brasília: CGU, 2017a.

CGU. Manual de Orientações Técnicas da Atividade de Auditoria Interna Governamental do Poder Executivo Federal. Brasília: CGU, 2017 b.

CGU. Instrução Normativa no 9, de 09 de outubro de 2018. Dispõe sobre o Plano Anual de Auditoria Interna - PAINT e sobre o Relatório Anual de Atividades de Auditoria Interna RAINT das Unidades de Auditoria Interna Governamental do Poder Executivo Federal e dá outras providências. Brasília: CGU, 2018a.

CHRIST, Margaret H. et al. Rotational internal audit programs and financial reporting quality: Do compensating controls help?. Accounting, Organizations and Society, v. 44, p. 37-59, 2015.

CIIA - CHARTERED INSTITUTE OF INTERNAL AUDITORS. Raising the profile of internal audit. CIIA, 2018. 
COETZEE, Philna; ERASMUS, Lourens J. What drives and measures public sector internal audit effectiveness? Dependent and independent variables. International Journal of Auditing, v. 21, n. 3, p. 237-248, 2017.

DELOITTE. The broken triangle? Improving the relationship between internal audit, management, and the audit committee. Deloitte, 2010.

DELOITTE. Auditoria Interna no Brasil - Rumo à consolidação do impacto e da influência . Deloitte, 2018.

D'ONZA, Giuseppe; LAMBOGLIA, Rita; VERONA, Roberto. Do IT audits satisfy senior manager expectations? A qualitative study based on Italian banks. Managerial Auditing Journal, v. 30, n. 4/5, p. 413-434, 2015.

EBIMOBOWEI, Appah. An evaluation of audit expectation Gap: Issues and challenges.

International Journal of Economic Development Research and Investment, v. 1, n. 2, 2010.

ERASMUS, Lourens; COETZEE, Philna. Drivers of stakeholders' view of internal audit effectiveness: Management versus audit committee. Managerial Auditing Journal, v. 33, n. 1, p. $90-114,2018$.

FAUSTINO, Mayara Kênia da Silva; NASCIMENTO, Ítalo Carlos Soares do; COSTA, Wênyka Preston Leite Batista da. A contribuição da auditoria interna para a gestão empresarial: um estudo de caso aplicado em empresas do ramo salineiro da cidade de Mossoró/RN. Revista

Conhecimento Contábil -UERN/UFERSA, v. 3, n. 2, 2016.

FEIZIZADEH, Ahmad. Strengthening internal audit effectiveness. Indian Journal of Science and Technology, v. 5, n. 5, p. 2777-2778, 2012.

GESTOR. [Entrevista cedida a] Lawrence Praxedes Mariz. Natal, 2019.

GRUPO FOCAL. [Entrevista cedida a] Lawrence Praxedes Mariz. Natal, 2019.

HASS, Susan; ABDOLMOHAMMADI, Mohammad J.; BURNABY, Priscilla. The Americas literature review on internal auditing. Managerial Auditing Journal, v. 21, n. 8, p. 835-844, 2006.

HUMPHREY, Christopher; MOIZER, Peter; TURLEY, Stuart. The audit expectations gap Plus ça change, plus c'est la même chose?. Critical perspectives on accounting, v. 3, n. 2, p. 137-161, 1992.

IFRN. Resolução no 066, de 31 de agosto de 2009. Aprova o Estatuto do Instituto Federal de Educação, Ciência e Tecnologia do Rio Grande do Norte. Natal: IFRN, 2009.

IFRN. Resolução no 09, de 23 de maio de 2014. Aprova a Reestruturação Funcional da Auditoria Geral do IFRN. Natal: IFRN, 2014a.

IFRN. Resolução n ${ }^{\circ} 28$, de 31 de outubro de 2014. Aprova o Regimento da Auditoria Interna do Instituto Federal de Educação, Ciência e Tecnologia do Rio Grande do Norte. Natal: IFRN, 2014b. 
IFRN. Resolução $n^{\circ} 11$, de 22 de fevereiro de 2017. Aprova a inserção no PAINT/2017/AUDGE/IFRN, de ação específica para a temática do Programa Nacional de Acesso ao Ensino Técnico e Emprego - PRONATEC. Natal: IFRN, 2017a.

IFRN. Resolução nº 20, de 28 de março de 2017. Aprova o Relatório de Auditoria Interna RAINT 2017 do Instituto Federal de Educação, Ciência e Tecnologia do Rio Grande do Norte. Natal: IFRN, $2017 \mathrm{~b}$.

IFRN. Resolução nº 59, de 17 de novembro de 2017. Aprova o Plano Anual de Atividades de Auditoria Interna - PAINT 2018 do Instituto Federal de Educação, Ciência e Tecnologia do Rio Grande do Norte. Natal: IFRN, 2017c.

IFRN. Resolução $n^{\circ}$ 05, de 23 de março de 2018. Aprova o Relatório de Auditoria Interna RAINT 2018 do Instituto Federal de Educação, Ciência e Tecnologia do Rio Grande do Norte. Natal: IFRN, 2018a.

IFRN. Resolução nº 38, de 30 de novembro de 2018. Aprova o Plano Anual de Atividades de Auditoria Interna - PAINT 2019 do Instituto Federal de Educação, Ciência e Tecnologia do Rio Grande do Norte. Natal: IFRN, 2018 b.

IFRN. Manual da Auditoria Interna do IFRN. Natal: IFRN, 2018c.

IFRN. Resolução no 13, de 26 de março de 2019. Aprova o Relatório de Auditoria Interna RAINT 2019 do Instituto Federal de Educação, Ciência e Tecnologia do Rio Grande do Norte. Natal: IFRN, 2019a.

IFRN. Plano de Desenvolvimento Institucional: 2019-2026. Natal: IFRN, 2019b.

IFRN. Relatório de Auditoria no 3/2019 - AUDGE/RE/IFRN. Natal: IFRN, 2019c.

IBGC - Instituto Brasileiro de Governança Corporativa. Auditoria interna: aspectos essenciais para o conselho de administração. São Paulo: IBGC, 2018.

IIA - INSTITUTE OF INTERNAL AUDITORS. Meeting stakeholders expectations. Florida: IIA, 2012.

IIA - INSTITUTE OF INTERNAL AUDITORS. The pulse of the profession - enhancing value through collaboration: a call to action. Florida: IIA, 2014.

IIA - INSTITUTO DOS AUDITORES INTERNOS DO BRASIL. Normas Internacionais para a Prática Profissional de Auditoria Interna, 2017. Disponível em: < https://iiabrasil.org.br//ippf/normas-internacionais>. Acesso em: 18 de outubro de 2018.

IIA - INSTITUTE OF INTERNAL AUDITORS. 2019 North American Pulse of Internal Audit: Defining Alingment in a Dynamic Rick Landscape. Florida: IIA, 2019.

JEDIDI, Imen; RICHARD, Chrystelle. The Social Construction of the Audit Expectation Gap: The Market of Excuses. In: La place de la dimension européenne dans la Comptabilité Contrôle Audit. 2009.

$\mathrm{KOH}$, Hian Chye; WOO, E.-Sah. The expectation gap in auditing. Managerial auditing journal, v. 13, n. 3, p. 147-154, 1998. 
MAFRA, Marcelo da Silva; SUAVE, Ricardo; GUILHERME, Jerónimo Taundi; ALBERTON, Luiz. Características da literatura internacional sobre auditoria governamental. Gestão e Sociedade, v. 9, n. 23, p. 926-945, 28 mar. 2016.

MARCONI, Marina de Andrade; LAKATOS, Eva Maria. Fundamentos de metodologia científica. 5 ed., São Paulo: Atlas, 2003.

MARÇOLA, Célia. Auditoria interna como instrumento de controle social na administração pública. Revista do Serviço Público, v.62, n.1, p.75-87, 2011.

OLIVEIRA, Robson Ramos; CARVALHO, Vânia Silva de. A produção científica sobre auditoria: um estudo bibliométrico a partir do caderno de indicadores da CAPES no período de 2004 a 2006. Pensar Contábil, v. 10, n. 42, 2008.

PIPER, Arthur. Auditing the Public Sector: Managing Expectations, Delivering Results. The Institute of Internal Auditors Research Foundation - IIARF, 2015.

PMI. Um guia do conhecimento em gerenciamento de projetos. Guia PMBOK® 6. ed. EUA: Project Management Institute, 2017.

PORTER, Brenda. An empirical study of the audit expectation-performance gap. Accounting and business research, v. 24, n. 93, p. 49-68, 1993.

PORTER, Brenda; GOWTHORPE, Catherine. Audit expectation-performance gap in the United Kingdom in 1999 and comparison with the Gap in New Zealand in 1989 and in 1999. Edinburgh: Institute of Chartered Accountants of Scotland, 2004.

PROTIVITI. Board Perspectives: Risk Ovesight. Protiviti, 2016.

PWC - PricewaterhouseCoopers Brasil. Os oito atributos - Execelência em Auditoria Interna. Brasil: PWC, 2017a.

PWC - PricewaterhouseCoopers. 2017 State of the Internal Audit Profession Study. PWC, $2017 \mathrm{~b}$.

PWC - PricewaterhouseCoopers Brasil. Perspectivas de auditoria interna. Brasil: PWC, 2017c.

PWC - PricewaterhouseCoopers Brasil. Estudo sobre a Prática Profissional de Auditoria Interna 2015. Brasil: PWC, 2017d.

RAUPP, Fabiano Maury; BEUREN, Ilse Maria. Metodologia da Pesquisa Aplicável às Ciências. Como elaborar trabalhos monográficos em contabilidade: teoria e prática. São Paulo: Atlas, 2006.

REZA, Mohammed Moin Uddin; KARIM, Md. Rezaul. Audit Expectation Gap - Evidence in 21st Century. International Journal of Science and Business, 2(4), 748-756, 2018.

ROUSSY, Mélanie. Internal auditors' roles: from watchdogs to helpers and protectors of the top manager. Critical Perspectives on Accounting, v. 24, n. 7-8, p. 550-571, 2013.

ROUSSY, Mélanie; PERRON, Alexandre. New perspectives in internal audit research: A structured literature review. Accounting Perspectives, v. 17, n. 3, p. 345-385, 2018.

Nucleus, v.18, n.1, abr. 2021 
SARENS, G.; BEELDE, I. de. The Relationship between Internal Audit and Senior Management: A Qualitative Analysis of Expectations and Perceptions. International Journal of Auditing, 10: 219-241, 2006.

TRAD, Leny A. Bomfim. Grupos focais: conceitos, procedimentos e reflexões baseadas em experiências com o uso da técnica em pesquisas de saúde. Physis, Rio de Janeiro, v. 19, n. 3, p. 777-796, 2009.

WEBSTER, Bruce. 20 Questions Directors Should Ask About Internal Audit. Chartered Professional Accountants of Canada, 3.ed., 2016.

\section{ROTEIRO DE ENTREVISTA - GRUPO FOCAL}

\section{PLANEJAMENTO}

1 - Qual o papel da auditoria interna na gestão do IFRN?

2 - Como é realizado o planejamento das atividades da auditoria?

3 - Quais aspectos são considerados relevantes na elaboração do Plano de Atividades da Auditoria Interna - PAINT? De que forma ele dialoga com o planejamento estratégico do IFRN?

4 - Como é a relação entre a auditoria interna e a alta gestão?

\section{COMUNICAÇÃO DOS RESULTADOS}

5 - Como ocorre geralmente a comunicação entre à auditoria e os stakeholders (alta gestão e demais partes interessadas)? Esta é adequada?

6 - Caso haja relatos de problemas ou dificuldades, o que fazer para a comunicação surtir o efeito exigível para os envolvidos?

7 - Quais habilidades são necessárias para que o auditor evite problemas de comunicação?

\section{EMISSÃO DE OPINIÃO}

8 - No momento da elaboração do relatório, quais aspectos são considerados para a elaboração do documento?

9 - Quais aspectos podem influenciar na emissão de uma recomendação?

10 - Como as expectativas da parte auditada e da alta gestão podem influenciar na emissão de uma opinião?

\section{PAPEL DO CHEFE DA AUDITORIA}

11 - Considerando a relação entre a alta gestão e a unidade de auditoria interna do IFRN, qual a contribuição do chefe da auditoria para o aprimoramento dessa relação?

12 - Quais os atributos que o chefe da auditoria deve possuir para construir uma relação positiva com os gestores?

\section{ATUAÇÃO DOS AUDITORES}

13 - O que os auditores podem realizar para que a auditoria interna seja percebida como agregadora de valor à gestão?

14 - Qual a percepção de vocês sobre as expectativas dos stakeholders com relação ao papel e responsabilidade? Citar exemplos como: mudança de postura dos auditores e da atuação da auditoria (proatividade); necessidade de assessoramento com relação à gestão de riscos; e situações de desconhecimento por parte dos gestores (solicitação de atividades operacionais e de cogestão). 
15 - O que é necessário para que haja alinhamento de expectativas entre auditoria interna e stakeholders?

16 - Qual o papel dos auditores com relação ao desalinhamento de expectativas?

17 - De que forma a auditoria interna muda e promove mudança à luz do que é necessário para a instituição?

ROTEIRO ENTREVISTA INDIVIDUAL - CHEFE DA AUDITORIA GERAL

\section{PLANEJAMENTO}

1 - Qual o papel da auditoria interna na gestão do IFRN?

2 - Como é realizado o planejamento das atividades da auditoria?

3 - Quais aspectos são considerados relevantes na elaboração do Plano de Atividades da Auditoria Interna

- PAINT? De que forma ele dialoga com o planejamento estratégico do IFRN?

4 - Como é a relação entre a auditoria interna e a alta gestão?

\section{COMUNICAÇÃO DOS RESULTADOS}

5 - Como ocorre geralmente a comunicação entre à auditoria e os stakeholders (alta gestão e demais partes interessadas)? Esta é adequada?

6 - Caso haja relatos de problemas ou dificuldades, o que fazer para a comunicação surtir o efeito exigível para os envolvidos?

7 - Quais habilidades são necessárias para que o Auditor-Chefe evite problemas de comunicação?

\section{EMISSÃO DE OPINIÃO}

8 - No momento da revisão de relatórios, quais aspectos são considerados para essa análise?

9 - Quais aspectos podem influenciar na emissão de uma recomendação?

10 - Como as expectativas da parte auditada e da alta gestão podem influenciar na emissão de uma opinião?

\section{PAPEL DO AUDITOR-CHEFE}

11 - Considerando a relação entre a alta gestão e a unidade de auditoria interna do IFRN, qual a contribuição do chefe da auditoria para o aprimoramento dessa relação?

12 - Quais os atributos que o chefe da auditoria deve possuir para construir uma relação positiva com os gestores?

\section{ATUAÇÃO DOS AUDITORES}

13 - O que os auditores podem realizar para que a auditoria interna seja percebida como agregadora de valor à gestão?

14 - Qual a sua percepção sobre as expectativas dos stakeholders com relação ao papel e responsabilidade da unidade de auditoria interna do IFRN? Citar exemplos como: mudança de postura dos auditores e da atuação da auditoria (proatividade); necessidade de assessoramento com relação à gestão de riscos; e situações de desconhecimento por parte dos gestores (solicitação de atividades operacionais e de cogestão).

15 - O que é necessário para que haja alinhamento de expectativas entre auditoria interna e stakeholders?

16 - Qual o papel dos auditores com relação ao desalinhamento de expectativas? Existe algum caso percebido em que auditores estejam ocasionando desalinhamento

17 - De que forma a auditoria interna muda e promove mudança à luz do que é necessário para a instituição?

Nucleus, v.18, n.1, abr. 2021 